\author{
한우 암소의 개체별 성장곡선 모수 추정 \\ 이창우*최재관*.전기준*나기준*이채영**.황정미***.김병완***.김종복*** \\ 농촌진흥청 축산기술연구소*, 한림대학교 환경생명과학연구소**, \\ 강원대학교 동물자원과학대학 동물자원학부***
}

\title{
Estimation of Parameters for Individual Growth Curves of Cows in Bostaurus Coreanae
}

C. W. Lee*, J. G. Choi*, G. J. Jeon*, K. J. Na*, C. Lee**, J. M. Hwang***, B. W. Kim*** and J. B. Kim***

National Livestock Research Institute, R.D.A*, Institute of Environment \& Life Science, Hallym University**, Division of Animal Resources Science, College of Animal Resources Science, Kangwon National University***

\begin{abstract}
Weight records of Hanwoo cows from birth to 36 months of age collected in Daekwanryeong branch, National Livestock Research Institute(NLRI) were fitted to Gompertz, von Bertalanffy and Logistic functions.

For the growth curve parameters fitted on individual records using Gompertz model, the mean estimates of mature weight(A), growth ratio(b) and growth rate(k) were $383.42 \pm 97.29 \mathrm{~kg}, 2.374 \pm 0.340$ and $0.0037 \pm 0.0012$, respectively, and mean estimates of body weight, age and daily gain rate at inflection were $141.05 \pm 35.79 \mathrm{~kg}, 255.63 \pm 109.09$ day and $0.500 \pm 0.123 \mathrm{~kg}$, respectively. For von Bertalanffy model, the mean estimates of $\mathrm{A}, \mathrm{b}$ and $\mathrm{k}$ were $410.47 \pm 117.98 \mathrm{~kg}, 0.575 \pm 0.057$ and $0.003 \pm 0.001$, and mean estimates of body weight, age and daily gain at inflection were $121.62 \pm 34.94 \mathrm{~kg}, 211.02 \pm 105.53$ and $0.504 \pm 0.124 \mathrm{~kg}$. For Logistic model, the mean estimates of A, b and k were $347.64 \pm 97.29 \mathrm{~kg}, 6.73 \pm$ 0.34 and $0.006 \pm 0.0018$, and mean estimates of body weight, age and daily gain at inflection were $173.82 \pm 37.25 \mathrm{~kg}, 324.47 \pm 126.85$ and $0.508 \pm 0.131 \mathrm{~kg}$.

Coefficients of variation for the A, b and k parameter estimates were $25.3 \%, 14.3 \%$ and $32.4 \%$, respectively, for Gompertz model, $28.7 \%$, $9.9 \%$ and $33.3 \%$ for von Bertalanffy model, and $27.9 \%$, $5.0 \%$ and $30.0 \%$ for Logistic model.
\end{abstract}

(Key words : Hanwoo, Cow, Growth curve, Growth models)

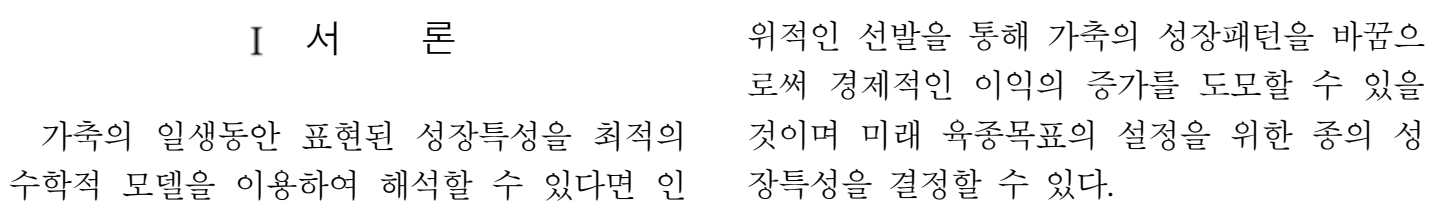

Corresponding author : C. W. Lee, Daekwanryong Branch, National Livestock Research Institute Rural Development Administration, 268, Chahang, Doam, Phyongchang, Kangwon, 232-952, Korea, Tel : 033330-0624, E-mail : k97112603@hotmail.com 
한 개체의 체중은 그 개체가 생존하는 동안 에 시간적인 간격을 두고 반복해서 측정할 수 있는데 이러한 개체가 일생동안 표현한 반복 측정기록(Longitudinal)의 해석은 난해하고 해 석된 성장특성치 사이에 일반적으로 높은 상 관관계가 있다.

그리고 시간적인 간격을 두고 반복 측정된 기록(Fitzhugh, 1976)들은 비선형의 변화를 보이 게 되는데 이러한 비선형의 관계를 해석할 수 있는 수리적인 기법으로 각종 성장곡선 모형이 개발되어 활용되고 있으나 성장곡선 모형의 모 수를 추정할 때 성숙체중에 도달하기 전에 도 태된 개체가 분석에 포함되면 수렴의 정도가 확실치 않다(Morrow, 1978).

따라서 본 연구는 축산기술연구소 대관령지 소에서 출생한 한우 암소로부터 시간적인 간격 을 두고 조사된 체중측정 기록에 대해 비선형 의 성장곡선 모형을 적용하여 한우 암소의 개 체별 성장곡선 모수를 추정하고 개체별로 추정 된 모수를 이용하여 한우 암소의 정확한 성장 형태를 추정하기 위해 실시하였다.

\section{ㅍ 재료 및 방법}

본 연구에서 분석한 재료는 1970년부터 2001 년까지 축산기술연구소 대관령지소에서 출생한 한우 암소 1,083 두로부터 조사된 일령별 체중 측 정자료였으며 개체별로 특정된 체중에 대한 성 장곡선 함수의 추정은 SAS(1990)의 비선형 회귀 분석 절차인 PROC NLIN을 이용하였으며, 편도 함수의 지정이 필요하지 않은 탐색 기법인 다변 량정활반복법(Multivariate Secant iterative method), 흔히 DUD방법(Doesn't Use Derivative)이라 부르 는 방식에 의하여 추정하였다. 추정에 있어 수렴 기준(convergence criterion)은 다음과 같다.

$$
\left(\mathrm{SSE}_{i-1}-\mathrm{SSE}_{i}\right) /\left(\mathrm{SSE}_{i}+10^{-8}\right)<10^{-10}
$$

여기에서 $\mathrm{SSE}_{i}$ 는 $i$ 번째 반복(interation)시의 오 차 제곱합이다.

본 연구에서 개체별로 성장곡선 모수를 추정하 기 위해 이용된 성장곡선 모형은 Gompertz 모형 (Winsor, 1932), von Bertalanffy 모형(von Ber- talanffy, 1957) 및 Logistic 모형(Nelder, 1961) 3개 였으며 성장곡선 모수추정은 체중 측정시 일령을 독립변수로 하여 실시하였는데, 우선 1,083 두의 개체별 체중측정 자료를 합하여 하나의 자료로 보고 성장곡선 모수 및 성장 특성치를 추정하고 이어 개체별로 성장곡선 모수를 추정하였다.

$$
\begin{array}{lll}
\text { Gompertz model } & : & W_{t}=A e^{-b e^{-k t}} \\
\text { von Bertalanffy model } & : & W_{t}=A\left(1-b e^{-k t}\right)^{3} \\
\text { Logistic model } & : & W_{t}=A\left(1+b e^{-k t}\right)^{-1}
\end{array}
$$

위의 모형에서 $\mathrm{A}$ 는 일령이 무한대인 시점 $(\mathrm{t}$ $=\infty$ ㅔㅔ서의 체중, $\mathrm{b}$ 는 생시체중과 성숙체중 비율 의 함수, $\mathrm{k}$ 는 생시체중, 변곡점체중, 성숙체중 및 변곡점 도달일령의 비율 함수로 $\mathrm{k}$ 가 크면 조숙성 으로 그리고 $\mathrm{k}$ 가 작으면 만숙성으로 판단된다.

개체별로 추정된 성장곡선 모수들에 대해서 는 각각 정규성 검정을 통해 성숙체중 $(\mathrm{A})$ 이 $1000 \mathrm{~kg}$ 이상이거나 성장비(b)가 19이상으로 추 정된 모수를 갖는 개체의 자료는 이상 수치로 판단되어 추가의 분석에서 제외시켰는데, 이상 수치를 갖는 개체의 자료를 제거한 후 남은 개 체의 자료는 Gompertz 모형이 1,064두분, von Bertalanffy 모형이 1,056두분, 그리고 Logistic 모형이 1,074 두 분이었다.

개체별로 추정한 성장곡선 모수를 이용하여 한우 암소의 정확한 성장형태를 추정하기 위해 변곡점, 변곡점체중 및 최대증체율을 구하였는 데, 변곡점은 성장곡선의 기울기가 최대가 되 는 일령, 변곡점 체중은 성장곡선의 기울기가 최대가 되는 시점의 체중, 최대증체율은 변곡 점에서의 일당증체량이다.

\section{III 결과 및 고찰}

개체별로 추정한 Gompertz 모형의 성장곡선 모수 $\mathrm{A}, \mathrm{b}$ 및 $\mathrm{k}$ 와 성장곡선의 변곡점, 변곡점 에서의 체중 및 일당증체량의 평균치와 표준편 차를 Table 1에 표시하였다.

Gompertz 모형으로 추정한 개체별 성장 곡선 모수 $\mathrm{A}, \mathrm{b}$ 및 $\mathrm{k}$ 의 변이계수는 각각 $25.3,14.3$ 및 $32.4 \%$ 이었다.

한편 조(2000)는 Gompertz 모형을 이용하여 
Table 1. Means and their standard deviations(SD) of growth curve parameters using Gompertz model

\begin{tabular}{lccc}
\hline \multicolumn{1}{c}{ Traits $^{2)}$} & $\mathrm{N}$ & Mean & SD \\
\hline \hline $\mathrm{A}^{1)}$ & 1,064 & 383.42 & 97.29 \\
$\mathrm{~b}$ & & 2.374 & 0.340 \\
$\mathrm{k}$ & & 0.0037 & 0.0012 \\
Weight at inflection, kg & & 141.05 & 35.79 \\
Age at point of inflection, day & & 255.63 & 109.09 \\
Gain at inflection, kg/day & 0.500 & 0.123 \\
\hline
\end{tabular}

${ }^{1)} \mathrm{A}, \mathrm{b}$ and $\mathrm{k}$ are fitted parameters for mature weight, growth ratio and maturing rate, respectively.

${ }^{2)}$ Growth parameters estimated for each cow.

1990년부터 1996년 사이에 출생한 한우 수소 1,133 두의 개체별 성장곡선을 추정한 결과 성장 곡선 모수 $\mathrm{A}, \mathrm{b}$ 및 $\mathrm{k}$ 의 평균 \pm 표준편차는 각각 $767.16 \pm 119.69 \mathrm{~kg}, \quad 3.4074 \pm 0.3903$ 및 $0.1083 \pm$ 0.0209 이었고 변곡점 도달월령 및 변곡점 체중 의 평균 \pm 표준편차는 각각 $11.59 \pm 2.05$ 개월 및 $282.22 \pm 44.03 \mathrm{~kg}$ 으로 보고한 바 있는데, 조 (2000)의 성장곡선 모수 추정치 $\mathrm{A}, \mathrm{b}, \mathrm{k}$ 의 평균 과 표준편차를 통해 변이 계수를 계산하면 A, $\mathrm{b}$ 및 $\mathrm{k}$ 의 변이계수는 각각 $15.6,11.4$ 및 $19.2 \%$ 가 된다. 본 연구에서 얻어진 결과는 조(2000) 의 결과에 비해 성장곡선 모수 $\mathrm{A}, \mathrm{b}$ 및 $\mathrm{k}$ 가 모 두 작고 $\mathrm{A}, \mathrm{b}$ 및 $\mathrm{k}$ 의 변이계수는 크며 변곡점 도달 시점은 빠른 편이었다.

von Bertalanffy 모형에 의해 개체별로 추정 한 성장곡선 모수 $\mathrm{A}, \mathrm{b}$ 및 $\mathrm{k}$ 와 성장곡선의 변 곡점, 변곡점에서의 체중 및 일당증체량의 평 균치와 표준편차를 Table 2에 표시하였다.

von Bertalanffy 모형으로 추정한 개체별 성 장곡선 모수 $\mathrm{A}, \mathrm{b}$ 및 $\mathrm{k}$ 의 변이계수는 각각
28.7, 9.9 및 33.3\%로 추정되었다.

Brown 등(1976)은 Hereford 순종 및 Hereford 종과 Brahman종의 교잡종 암소 147 두와 Jersey 종 암소 151두에 대해 von Bertalanffy 모형으 로 성장곡선을 추정한 결과, 성숙체중 $(\mathrm{A})$ 의 경 우 교잡종 암소 및 Jersey종 암소가 각각 499 및 $416 \mathrm{~kg}$ 이였고, 성장비(b)의 경우 각각 0.56 및 0.56 이였으며, 성숙률 $(\mathrm{k})$ 의 경우 각각 0.090 및 0.064 였다고 보고한 바 있는데, 본 연구에서 추정된 A, b, k를 Brown 등(1976)의 결과와 비 교해보면 A는 Hereford종보다 작으나 Jersey종 과는 큰 차이가 없으며, $\mathrm{b}$ 는 Hereford종이나 Jersey종보다 약간 큰 편이고 $\mathrm{k}$ 는 Hereford종이 나 Jersey종보다 작은 것으로 판단된다.

한편 Lopez 등(1992)은 8개월령에서 97개월 령까지 측정된 스페인 지역의 Retinta종 암소 50 두의 체중 - 연령 자료에 대해 von Bertalanffy모 형으로 성장곡선을 추정한 결과, 성장곡선 모 수 $\mathrm{A}, \mathrm{b}$ 및 $\mathrm{k}$ 의 변이계수가 각각 $5 \%, 15 \%$ 및 $21 \%$ 이었다고 보고한 바 있는데, 본 연구에서

Table 2. Means and their standard deviations(SD) of growth curve parameters using von Bertalanffy model

\begin{tabular}{lccc}
\hline \multicolumn{1}{c}{ Traits $^{2)}$} & $\mathrm{N}$ & Mean & SD \\
\hline \hline $\mathrm{A}^{1)}$ & 1,056 & 410.47 & 117.98 \\
$\mathrm{~b}$ & & 0.575 & 0.057 \\
$\mathrm{k}$ & & 0.0030 & 0.0010 \\
Weight at inflection, $\mathrm{kg}$ & 121.62 & 34.94 \\
Age at point of inflection, day & & 211.02 & 105.53 \\
Gain at inflection, $\mathrm{kg} /$ day & & 0.504 & 0.124 \\
\hline
\end{tabular}

1) A, b and $\mathrm{k}$ are fitted parameters for mature weight, growth ratio and maturing rate, respectively.

2) Growth parameters estimated for each cow. 
Table 3. Means and their standard deviations(SD) of growth curve parameters using Logistic model

\begin{tabular}{lccc}
\hline Traits $^{2)}$ & $\mathrm{N}$ & Mean & SD \\
\hline \hline $\mathrm{A}^{1)}$ & 1,074 & 347.64 & 97.29 \\
$\mathrm{~b}$ & & 6.73 & 0.34 \\
$\mathrm{k}$ & & 0.0060 & 0.0018 \\
Weight at inflection, kg & 173.82 & 37.25 \\
Age at point of inflection, day & 324.47 & 126.85 \\
Gain at inflection, kg/day & 0.508 & 0.131 \\
\hline
\end{tabular}

1) $\mathrm{A}, \mathrm{b}$ and $\mathrm{k}$ are fitted parameters for mature weight, growth ratio and maturing rate, respectively.

2) Growth parameters estimated for each cow.

추정된 $\mathrm{A}, \mathrm{b}$ 및 $\mathrm{k}$ 의 변이계수는 Lopez 등 (1992)이 보고한 결과에 비해 큰 편이었다.

Logistic 모형에 의해 개체별로 추정한 성장 곡선 모수 $\mathrm{A}, \mathrm{b}$ 및 $\mathrm{k}$ 와 성장곡선의 변곡점, 변 곡점에서의 체중 및 일당증체량의 평균치와 표 준편차를 Table 3에 표시하였다.

Logistic 모형으로 추정한 개체별 성장곡선 모수 $\mathrm{A}, \mathrm{b}$ 및 $\mathrm{k}$ 의 변이계수는 각각 $27.9,5.0$ 및 $30.0 \%$ 였다.

Brown 등(1976)은 Hereford 순종 및 Hereford 종과 Brahman종의 교잡종 암소 147 두와 Jersey 종 암소 151두에 대해 Logistic 모형으로 성장 곡선을 추정한 결과, 성숙체중 $(\mathrm{A})$ 의 경우 교잡종 암소 및 Jersey종 암소가 각각 480 및 $401 \mathrm{~kg}$ 이었 고, 성숙률(k)의 경우 교잡종 암소 및 Jersey종 암소가 각각 0.116 및 0.086 이라고 보고한 바 있 는데, 본 연구에서 추정된 $\mathrm{A}$ 와 $\mathrm{k}$ 는 Brown 등 (1976)의 결과에 비해 작은 편이었다.

본 연구에서 모형별로 추정된 성장곡선 모수 및 성장곡선 모수들의 변이계수를 서로 비교해 보면 성숙체중은 von Bertalanffy 모형이 그리고 성장비와 성숙률은 Logistic 모형이 큰 편이었다. 성장곡선 모수들의 변이계수를 보면 모형별로 $\mathrm{A}$ 는 25.3 $\quad$ 4.3\% 그리고 $\mathrm{k}$ 는 30.0 3.6\%의 범위였는데, Gompertz 모형으로 추정된 모수 $\mathrm{b}$ 의 변이계수가 von Bertalanffy 모 형으로 추정된 모수 $\mathrm{b}$ 나 Logistic 모형으로 추정 된 모수 $\mathrm{b}$ 의 변이 계수들보다 큰 편이었다.

그리고 세 모형으로 추정한 변이계수들을 Lopez 등(1992)이 Retinta종 암소에서 보고한 $\mathrm{A}, \mathrm{b}$ 및 $\mathrm{k}$ 의 변이계수 5, 15 및 $21 \%$ 나 Kaps
등(1999, 2000)이 Angus종 암소에서 보고한 A 와 $\mathrm{k}$ 의 변이계수 $12.5 \%$ 와 $19.7 \%$, 그리고 조 (2000)가 보고한 한우 수소의 A, b 및 k의 변 이계수 $15.6 \%, 11.4 \%$ 및 $19.2 \%$ 와 비교해보면 본 연구결과 얻어진 $\mathrm{A}$ 와 $\mathrm{k}$ 의 변이계수가 큰 편이 었는데, 그 원인중의 하나로 생각할 수 있는 것 은 본 연구에서 조사된 자료는 1970년도부터 2001년까지 출생된 개체들로부터 얻어졌는 바 다른 연구자들이 분석한 자료에 비해 비교적 조 사기간이 길었던 관계로 그만큼 성장곡선의 모 양이 더 많이 변하였기 때문이라고 판단된다.

본 연구에서 얻어진 한우 암소의 모형별 성 장곡선 모수 및 성장 특성치들을 한우 수소에 서 얻어진 타 연구자들의 결과와 비교해볼 때, 한우 암소는 수소에 비해 생시체중에 대한 성 숙체중의 비율이 낮고 변곡점까지 도달일령이 빠르며 변곡점 도달시 체중도 작은 것으로 판 단되며 외국의 육우 암소에서 조사된 타 연구 자들의 연구 결과와 비교해볼 때, Hereford종, Retinta종 및 Workalup종과 같은 육우 암소나 Jersey종과 같은 유우 암소에 비해 성숙체중이 작고 성숙률도 늦는 것으로 판단된다.

Table 4는 일령에 대해 보정을 한 실제 체중 과 세 모형에 의해 추정된 생시, 3 개월령, 6 개 월령, 12 개월령, 18 개월령, 24 개월령 및 36 개월 령의 평균 체중을 표시하였다.

생시체중의 경우 Gompertz 모형, von Bertalanffy 모형 및 Logistic 모형에 의해 추정된 평 균치들은 각각 $36.40 \pm 0.33, \quad 31.59 \pm 0.34$ 및 $49.09 \pm 0.88 \mathrm{~kg}$ 으로서 실제체중 $23.73 \pm 0.10 \mathrm{~kg}$ 보 다 컸으며, 36 개월령 체중의 경우 세 모형이 
Table 4. Observed(OBW) and estimated(EBW) body weights by ages

(Unit : kg)

\begin{tabular}{crrrr}
\hline \multirow{2}{*}{ Age } & \multirow{2}{*}{ OBW } & \multicolumn{3}{c}{ EBW(Mean \pm SE) } \\
\cline { 3 - 5 } & & \multicolumn{1}{c}{ Gompertz } & von Bertalanffy & \multicolumn{1}{c}{ Logistic } \\
\hline \hline Birth & $23.73 \pm 0.10$ & $36.40 \pm 0.33$ & $31.59 \pm 0.34$ & $49.09 \pm 0.88$ \\
3 month & $68.16 \pm 0.47$ & $68.97 \pm 0.38$ & $68.59 \pm 0.38$ & $74.46 \pm 0.88$ \\
6 month & $119.05 \pm 0.74$ & $109.83 \pm 0.58$ & $111.85 \pm 0.59$ & $109.11 \pm 0.91$ \\
12 month & $192.93 \pm 1.24$ & $195.33 \pm 1.07$ & $195.97 \pm 1.05$ & $195.01 \pm 1.23$ \\
18 month & $258.36 \pm 1.36$ & $258.36 \pm 1.35$ & $257.36 \pm 1.33$ & $261.75 \pm 1.46$ \\
24 month & $304.74 \pm 1.65$ & $304.29 \pm 1.58$ & $304.39 \pm 1.57$ & $304.67 \pm 1.62$ \\
36 month & $363.67 \pm 2.08$ & $349.73 \pm 2.01$ & $356.41 \pm 2.07$ & $336.18 \pm 1.91$ \\
\hline
\end{tabular}

각각 $349.73 \pm 2.01, \quad 356.41 \pm 2.07$ 및 $336.18 \pm$ $1.91 \mathrm{~kg}$ 으로 실제체중 $363.67 \pm 2.08 \mathrm{~kg}$ 보다 작았 는데, 특히 Logistic 모형이 von Bertalanffy 및 Gompertz 모형에 비해 생시 및 36개월령에서 실제체중과의 차이가 심하였다. 이러한 결과와 더불어 Table 2에 표시된 모형별 오차 평균 제 곱합의 크기를 함께 고려해 볼때 한우 암소의 성장곡선을 추정하는데는 Logistic 모형이 Gompertz 모형이나 von Bertalanffy 모형에 비 해 적합도가 떨어지는 것으로 판단된다.

한편 Brown 등(1976)은 von Bertalanffy 모형, Gompertz 모형, Brody 모형, Logistic 모형 및 Richard 모형으로 모형간 적합도를 비교 분석 한 결과 성장초기 체중의 경우 von Bertalanffy 모형, Gompertz 모형 및 Logistic 모형에서 크 게 추정되고, 성숙체중의 경우 Logistic 모형에 서 작게 추정되는 경향이 보인다고 보고한 바 있는데, 세 모형 모두 생시체중과 36개월령 체 중을 작게 추정하며, 특히 Logistic 모형에 의한 36 개월령 체중 추정치가 Gompertz 모형이나 von Bertalanffy 모형에 의한 36개월령 체중 추정치보 다 더 작은 본 연구의 결과는 Brown 등(1976)의 보고와 부합되는 성적인 것으로 판단된다.

한우 암소의 월령별 체중 평균치에 대한 국내 의 연구 결과를 보면 최 등(1996)은 생시체중 및 24개월령 체중이 각각 $24.69 \pm 3.50$ 및 $354.32 \pm$ $6.93 \mathrm{~kg}$ 이라고 보고한 바 있고, 최(2001)는 생시, 3 개월령, 6 개월령, 12 개월령, 18 개월령, 24 개월령 체중이 각각 $24.97 \pm 3.48,76.37 \pm 14.01,129.59 \pm$ $22.33,214.34 \pm 38.35,281.96 \pm 49.19$ 및 $333.64 \pm$ $49.31 \mathrm{~kg}$ 이라고 보고한 바 있으며, 양 등(1990)은
생시, 6개월령, 12 개월령, 18 개월령 및 24개월령 체중이 각각 $22.49 \pm 0.42,147.18 \pm 6.17,223.48 \pm$ $6.26,267.76 \pm 5.74$ 및 $291.77 \pm 9.62 \mathrm{~kg}$ 이라고 보고 한 바 있다. 본 연구에서 얻어진 월령별 실측체 중의 평균치는 최(2001)의 보고에 비해 작았고, 양 등(1990)에 비해 크게 추정되었는데, 이렇게 차이가 나는 것은 출생지역 및 출생년도의 차이 가 하나의 원인일 것으로 판단된다.

$$
\text { IV 요 약 }
$$

출산기술연구소 대관령지소에서 출생한 한우 암소로부터 시간적인 간격을 두고 조사된 체중측 정 기록에 대해 비선형의 성장곡선 모형을 적용하 여 한우 암소의 개체별 성장곡선 모수를 추정하고 개체별로 추정된 모수를 이용하여 한우 암소의 정 확한 성장형태를 추정하기 위해 실시하였다.

Gompertz 모형으로 추정한 개체별 성장 곡선 모수 $\mathrm{A}, \mathrm{b}$ 및 $\mathrm{k}$ 의 평균치는 각각 $383.42 \pm$ $97.29 \mathrm{~kg}, \quad 2.374 \pm 0.340$ 및 $0.0037 \pm 0.0012$ 였으 며, 개체별 변곡점의 평균은 $255.63 \pm 109.09$ 일, 변곡점에서 체중의 평균은 $141.05 \pm 35.79 \mathrm{~kg}$, 변 곡점에서의 일당증체량의 평균은 $0.500 \pm 0.123$ $\mathrm{kg}$ 이었고, 성장곡선 모수 $\mathrm{A}, \mathrm{b}$ 및 $\mathrm{k}$ 의 변이계 수는 각각 25.3, 14.3 및 32.4\%이었다.

von Bertalanffy 모형으로 추정한 개체별 성장 곡선 모수 $\mathrm{A}, \mathrm{b}$ 및 $\mathrm{k}$ 의 평균치는 각각 $410.47 \pm$ $117.98 \mathrm{~kg}, 0.575 \pm 0.057$ 및 $0.003 \pm 0.001$ 이었고, 개체별 변곡점의 평균은 $211.02 \pm 105.53$ 일, 변 곡점에서 체중의 평균은 $121.62 \pm 34.94 \mathrm{~kg}$, 최대 증체율의 평균은 $0.504 \pm 0.124 \mathrm{~kg}$ 이었으며, 성장 
곡선 모수 $\mathrm{A}, \mathrm{b}$ 및 $\mathrm{k}$ 의 변이계수는 각각 28.7, 9.9 및 33.3\%로 추정되었다.

Logistic 모형으로 추정한 개체별 성장곡선 모 수 $\mathrm{A}, \mathrm{b}$ 및 $\mathrm{k}$ 의 평균치는 각각 $347.64 \pm 97.29 \mathrm{~kg}$, $6.73 \pm 0.34$ 및 $0.006 \pm 0.0018$ 이었고, 개체별 변 곡점의 평균은 $324.47 \pm 3.87$ 일, 변곡점에서 체 중의 평균은 $173.82 \pm 1.13 \mathrm{~kg}$, 최대 증체율의 평 균은 $0.508 \pm 0.003 \mathrm{~kg}$ 이었으며, 성장곡선 모수 $\mathrm{A}, \mathrm{b}$ 및 $\mathrm{k}$ 의 변이계수는 각각 $27.9,5.0$ 및 $30.0 \%$ 이었다.

Gompertz 모형, von Bertalanffy 모형 및 Logistic 모형에 의해 추정된 생시체중의 평균치들 은 각각 $36.40 \pm 0.33,31.59 \pm 0.34$ 및 $49.09 \pm$ $0.88 \mathrm{~kg}$ 으로 추정되어 실제체중 $23.73 \pm 0.10 \mathrm{~kg}$ 보다 컸으며 36 개월 체중의 경우 세 모형이 각 각 $349.73 \pm 2.01,356.41 \pm 2.07$ 및 $336.18 \pm 1.91 \mathrm{~kg}$ 으로 실제체중 $363.67 \pm 2.08 \mathrm{~kg}$ 보다 작았다.

그러나 세 모형으로 추정된 변곡점이 한우 암소의 실질적인 변곡점인지에 대해서는 좀더 검토가 필요한 부분인데, 최(2001)는 한우 암소 의 경우 3 개월령에서 4 개월령 사이의 일당증체 량이 0.590 으로서 이 시기에 최대의 성장이 이 루어지며 3 개월령 체중과 4 개월령 체중은 각각 79.31 및 $98.91 \mathrm{~kg}$ 이라고 보고하고 있으며, 본 연구에서 Table 4에 제시된 결과를 봐도 3개월 령과 6 개월령 사이 90 일 동안에 $50.89 \mathrm{~kg}$ 의 증 체가 이루어져 일당증체량으로 환산하면 약 $0.56 \mathrm{~kg}$ 이 되어 다른 어느 시기보다도 가장 증 체속도가 빠른 시기인 것으로 나타났다.

변곡점이 일당증체량이 최대인 시점으로 해석 한다면 각 모형에서 고정되어 있는 변곡점의 위 치들인 성숙체중의 $38.6 \%(G o m p e r t z$ 모형), $29.6 \%$ (von Bertalanffy 모형) 및 50\%(Logistic 모형)는 한 우 암소의 실질적인 변곡점보다 늦는 것으로 판 단할 수 있는데, 실제로 세 모형 중 변곡점의 위 치가 제일 빠른 von Bertalanffy 모형의 적합도가 제일 좋은 것도 이러한 이유 때문일 수 있다.

따라서 한우 암소의 정확한 성장특성을 파악 하기 위해서는 변곡점의 위치가 고정되어 있지 않은 기존의 모형들을 이용하는 방안과 아울러 본 연구에 이용된 모형들을 변형시켜 활용하는 방안에 대한 연구가 필요한 것으로 판단된다.
$\mathrm{V}$ 사 사

This work was supported by a grant from BioGreen 21 Program, Rural Development Administration, Republic of Korea.

\section{$\mathrm{VI}$ 인 용 문 헌}

1. Brown, J. E., Jr. Fizhugh, H. A. and Cartwright. T. C. 1976. A comparison of nonlinear models for describing weight-age relationships in cattle. J. Anim. Sci. 42:810-818.

2. Fitzhugh, H. A., Jr. 1976. Analysis of growth curves and strategies for altering their shape. J. Anim. Sci. 42:1036-1051.

3. Kaps, M., Herring, W. O. and Lamberson. W. R. 1999. Genetic and environmental parameters for mature weight in Angus cattle. J. Anim. Sci. 77:569574.

4. Kaps, M., Herring, W. O. and Lamberson. W. R. 2000. Genetic and environmental parameters for traits derived from the Brody growth curve and their relationships with weaning weight in Angus cattle. J. Anim. Sci. 78:1436-1442.

5. López de Torre, G., Candotti, J. J., Reverter, A., Bellido, M. M., Vasco, P., García, L. J. and Brinks, J. S. 1992. Effect of growth curve parameters on cow efficiency. J. Anim. Sci. 70:2668-2672.

6. Morrow, R. E., McLaren, J. B. and Butts, W. T. 1978. Effect of age on estimates of bovine growth curve parameters. J. Anim. Sci. 42:352-357.

7. Nelder. J. A. 1961. The fitting of a generalization of the logistic curve. Biometrics 17:89-100.

8. SAS. 1990. SAS/STAT User's guide Vol. 2. SAS institute Inc., Cary, NC., USA.

9. Von Bertalanffy, L. 1957. Quantitative laws in metabolism and growth. Quart. Rev. Biol. 32:217.

10. Winsor, C. R. 1932. The Gompertz curve as a growth curve. Proc. Natl. Acad. Sci. 18:1.

11. 양영훈, 오봉국. 1990. 한우의 체중과 흉위 및 전 관위에 대한 육종가 추정에 관한 연구. 한축지. 32(12):740-747.

12. 조용민. 2000. 한우의 성장곡선모수 추정 및 경 제형질과의 상관관계에 관한 연구. 서울대학교. 박사학위논문.

13. 최재관. 2001. 한우에서 성장단계별 체중의 유전 적 특성. 강원대학교. 박사학위 논문.

(접수일자 : 2003. 4. 17. / 채택일자 : 2003. 9. 29.) 